\title{
Environmental Sustainability of Oil Industry
}

\author{
Vera Rocca and Dario Viberti \\ Department of DIATI, Faculty of Engineering, \\ Politecnico di Torino, Corso Duca Degli Abruzzi 24, 10129 Torino, Italy
}

Received 2013-05-17, Revised 2013-05-23; Accepted 2013-06-03

\begin{abstract}
Similarly to most industrial activities, the oil industry can affect the environment at several stages. The greatest impact is the release of waste into the environment in concentrations that are not natural. Virtually in all cases, the adverse impact can be minimized or eliminated through the implementation of a proper waste management plan. Over the past few years the oil industry has placed greater emphasis on minimizing the environmental impact of its operations in all the main phases of a hydrocarbon reservoir life: from appraisal to field development, from production and recovery to reservoir decommissioning. As a consequence, the oil industry is facing important technical challenges, approaching with great interest and expectation new emerging technologies, such as nanotechnologies and alternative solutions, like $\mathrm{CO}_{2}$ underground storage. This study provides an overview of the most interesting solutions that have been proposed and critically highlights their potential benefits and drawbacks. The following paper focuses on some of the new approaches that have already changed the routine operation workflow, while others are currently being tested and may yet require further improvement.
\end{abstract}

Keywords: Oil Industry, Environmental Footprint, Waste Management

\section{INTRODUCTION}

Most of the easily recoverable oil and gas reserves have already been developed. Since the number of reservoirs discovered in extremely difficult environments is progressively increasing, conventional operations or technologies could become less efficient. Furthermore, growing environmental concerns have created a new awareness that is driving today's society, industries and governments towards a better safekeeping of our planet.

As a consequence, the oil industry is facing important technical challenges that make it move towards more efficient, less expensive and environmentally friendly solutions. Growing expectation is placed in new emerging technologies, such as nanotechnology, which has already offered some breakthroughs in innovative and environmentally friendly technologies in many other industrial fields (Cocuzza et al., 2012).

The greatest environmental impact of petroleum activities arises from the release of waste into the environment in a concentration that is not naturally found, compromising ground, air and water quality. Virtually in all cases, the adverse impact can be minimized or eliminated through the implementation of a proper waste management plan (Shaaban, 2000), which takes into consideration all the life phases of a hydrocarbon reservoir, until decommissioning. In fact, planning for decommissioning is an integral part of the overall management process and should be considered at the beginning of the development during the design phase, in both onshore and offshore operations.

\section{MATERIALS AND METHODS}

\subsection{Drilling}

Drilling activities start with the appraisal phase and involve all reservoir life: Appraisal wells aim to verify the presence of hydrocarbon and then to evaluate the size and nature of the reservoir; the production or injection wells allow reservoir development and, eventually,

Corresponding Author: Vera Rocca, Department of DIATI, Faculty of Engineering, Politecnico di Torino,

Corso Duca Degli Abruzzi 24, 10129 Torino, Italy 
production maintenance through gas/fluid injection. The location of a drill site depends not only on the characteristics of the underlying geological formations but also on surface constraints. It is generally possible to balance environmental protection criteria with logistical constraints, without compromising the efficiency of drilling. Nevertheless, most of the easily recoverable oil and gas reserves are already developed and new discoveries will be increasingly affected by protected area issues and extreme environmental conditions, with consequent impact on drilling logistics.

A part from logistic issues, the management of drilling fluid disposal and the assessment of discharge are crucial points during drilling. Muds are blended clay mineral suspensions with thixotropic properties; they usually have an Oil (OBM) or fresh-Water (WBM) base. During drilling activities, mud is circulated in hole annulus in order to maintain the stability of the hole and to remove the drill cuttings (i.e., a mixture of rock particles from formation sand residual drilling fluids) from the borehole (Swanston and Heffler, 1977). At the surface, drill solids are removed and the mud is partially recirculated and partially replaced by fresh materials. As a consequence large quantities of complex mixtures of oil, water and solids are produced and must be managed for environmental friendly disposal.

\subsection{Primary Production and Improved/ Enhanced Oil Recovery Methodologies}

In the early stage of conventional reservoir exploitation, the underground pressures drive the fluid free flow up to the surface. This phenomenon is known as primary production, i.e., production thanks to internal system energy. Because of system exploitation, production rate approaches the limit of profitable operation due to progressive system loss of energy: further reservoir exploitation can require the adoption of Improved Oil Recovery (IOR) and Enhanced Oil Recovery (EOR) techniques. IOR techniques consist in immiscible injection of gas or water to achieve higher recovery factors and prevent reservoir pressure and production rate from dropping excessively. EOR approaches are usually applied in heavy oil reservoir, they can be based on thermal processes, miscible gas injection methods or chemical processes (Novelli et al., 2005) These additional recovery methods are usually adopted in the final exploitation phase of conventional reservoirs and they allow an improvement in ultimate oil recovery. Since heavy oil is fluid characterized by low dissolved gas content and high viscosity, these unconventional reservoirs commonly require injection of gas, water or steam from the early phases of production life.

The environmental effects related to hydrocarbon primary production and additional recovery operations can potentially have an impact on both air and water quality and so they must be carefully evaluated and minimized with suitable environmental risk management.

In the development phase of an oil field, production of water and gas is often present and for obvious environmental reasons it must be disposed of. Since oil is the production target, separated gas that cannot be utilized for profit is usually flared bringing undesirable atmospheric emissions that include: $\mathrm{CO}, \mathrm{CO}_{2}, \mathrm{SO}_{2}$, H2S, NOx and particulates (PM2.5 and PM10) (Ashiedu and Olarewaju-Alo, 1998). The air quality issue is even more critical for the steam-based thermal EOR technologies adopted for the production of heavy oil, extra heavy oil and bitumen, due to toxic emissions related to steam generators.

The management of produced water waste associated to hydrocarbon extraction is an additional crucial point in a proper waste management plan: even if development production strategies focus on water production minimization, a significant percentage of water could be associated with primary production. This phenomenon becomes particularly critical during IOR and EOR applications: A great number of these technologies, in fact, require the injection of a large amount of water, which is used both as displacing phase and as carrier vector for active agents, such as chemicals. The injected water is produced again, together with the displaced oil. Such water contains Total Petroleum Hydrocarbons (TPH), total suspended solids, chlorides and sulphide (Khan et al., 2005) thus their disposal into the environment could be hazardous.

In case of chemical flooding, environmental concerns due to the toxicity of the chemical complicate water disposal activities.

\subsection{Reservoir Characterization and Data Acquisition}

The definition of an optimal reservoir exploitation strategy requires a proper reservoir characterization, i.e., estimation of some crucial rock properties such as porosity, fluids saturations, permeability, heterogeneities, Porosity and fluids saturations are mainly obtained through the so called well logs interpretation process (Viberti and Verga, 2012). Well logs are measurements of physical parameters such as natural radioactivity, 
electrical resistivity, density. Permeability is obtained through interpretation of well testing.

Well tests have been widely used in the oil industry for several decades to estimate reservoir characteristics as the initial pressure, fluid type and effective permeability as well as to identify reservoir barriers or boundaries in the formation volume investigated by the test (Coelho et al., 2005). Conventional well testing methods usually involve surface production of fluids. In exploration and often in appraisal scenarios, surface facilities to store the reservoir fluids are not available and hence the fluid is discharged or flared. The effect is the emission of significant amounts of unburned hydrocarbons, carbon monoxide and nitrogen oxides, which in turn produce acid rain, smog, ozone at ground levels and greenhouse gases in the upper atmosphere (Verga and Rocca, 2010). Unconventional well-test methods have been proposed in order to overcome the emission issues. Among the different adopted technologies, several could be potentially hazardous for the environment.

\section{RESULTS AND DISCUSSION}

\subsection{Drilling}

Drilling technology has been moving toward more efficient, less expensive and environmentally friendly solutions. Thanks to directional drilling techniques, a number of deviated wells drilled from a single site can reach spatially distant hydrocarbon bearing formations. Multilateral drilling takes horizontal or directional drilling one step further, by drilling multiple directional wells from the same wellbore (Godec and Johnson, 2005). These technologies, in turn, can substantially decrease the surface impacts associated with drilling operations and allow production from reservoirs otherwise inaccessible via normal vertical drilling due to environmental constraints.

Recent technologies, such as slimhole drilling technique and coiled tubing, results in lower costs, lower waste volumes, smaller environmental footprints, reduced noise and visual impacts and fuel consumption. Nevertheless, even if this technique does not fully replace the traditional drilling operations, it can be used successfully in early stages of exploitation, in delineating newly discovered prospects, in re-entering existing wells with small diameter wellbores to trap new reserve in mature fields, (Godec and Johnson, 2005).

For the past three decades research has been facing environmental regulations for the use of oil based mud, promoting the adoption of plant oils as diesel substitutes. The contribution of non-edible oil-such as, Rapeseed oil, Jatropa oil, Mahua oil, Cottonseed oil, Sesame oil, Soya bean oil, palm oil, (Adesina et al., 2012)-has been widely investigated. As an example, in (Xiaoqing and Lihui, 2009) developed drilling fluids mainly composed by shale inhibitor agents and fluid loss control agent derived from vegetal gum, bloomless white asphalt and dry powders of poly alcohols. They do not have any toxic components and they are all biodegradable. Such drilling fluids have been successfully employed in the Tarim oil field, in the Taklimakan desert in northwest China and in ShengLi oil field with strong sea discharge requirements. Amin et al. (2010) tested several esters as the external phase of an invert emulsion, derived from Malaysian biodiesel plants. Esters were first field trialed offshore Norway. However they showed limited applications in invert drilling fluids due to their physical and chemical properties, such as high susceptibility to hydrolysis (Amin et al., 2010).

Water Based Muds (WBMs) represent a viable alternative to OBMs especially in sensitive environmental regions. Nevertheless, WBMs effective benefit must be carefully evaluated according to system characteristics: In presence of particular clay minerals (i.e., smectite) they could induce time-dependent wellbore instability phenomena, such as wall swelling with consequent formation breakdown and pipe track, which can be so severe to compel the wellbore abandonment.

A crucial point in environmental footprint reduction is represented by disposal of exhausted mud and cuttings due to well drilling operations. For land-based activities, the drilling waste is collected in an excavated sump which at the completion of the drilling operation is back filled and the landscape restored. This approach becomes more and more expensive and logistically complicated according to increase in well length and numbers. Slurrification and injection of drilling generated waste into selected subsurface formations through initiation of disposal fractures was first used back in 1988. The industry has gained experience and know-how since then and therefore slurrification and injection have become the technology of choice for drilling operations in many $\mathrm{E}$ andP regions (Gogan et al., 2010).

\subsection{Well Test}

Due to more restrictive environmental regulations and a general need to reduce operating expenses, the current industry drivers in formation evaluation 
methodologies demand short, cost-effective and environmentally friendly well test procedures, especially in exploration wells. This is particularly true in deepwater and arctic environments where conventional tests can be prohibitively expensive or logistically not feasible (Soliman et al., 2005) as well as in several protected areas of the world where no emissions are allowed to the surface. Some of the main alternatives to conventional well test are Production-reinjection testing, Injection testing and Wireline formation testing (Verga and Rocca, 2010).

\subsection{Production-Reinjection Testing}

The Downhole Production/reinjection Test (DPT) method is a well test procedure that allows production from a selected layer (production layer) and injection of the produced volume into another adequate zone (injection zone) through a downhole pump. All the test parameters, such as flow rates, pressure and temperature data are monitored and controlled from the surface. This methodology permits to test both production and injection layers and to collect fluid samples (Woie et al., 2000; Hollaender et al., 2002).

The production/reinjection test method significantly reduces the onshore and offshore logistics operations and the corresponding costs. Furthermore, the environmental and safety issues are significantly reduced because no hydrocarbons flow to surface during the test (Woie et al., 2000; Hollaender et al., 2002). Despite the environmental and economic advantages, the applicability of the methodology has to be carefully evaluated for each case, since a number of technical disadvantages could occur.

\subsection{Injection Testing}

An injection test consists substantially in injecting a fluid, commonly a brine or diesel, in a potential oil pay zone and in monitoring the pressure response during the injection period and the subsequent so called fall-off period, in which the well is shut in and the pressure tends to return to the equilibrium value. As a consequence, injection tests eliminate emissions during reservoir appraisal and, except for fluid sampling, can provide all the information needed to estimate the well productivity at a reasonably low cost and with a good degree of reliability (Levitan, 2002; Beretta et al., 2007). Since the physical phenomena characterizing injection test are different with respect to the conventional well test, numerical models capable to provide a reliable interpretation of the data have been developed over the last years (Verga et al., 2008; 2011; 2012; Cancelliere and Verga, 2012). An example of successful field experiences was presented in the study by Beretta et al. $(2006 ; 2007)$.

\subsection{Wireline Formation Testing}

Wireline Formation Testing (WFT) consists in producing the reservoir fluids directly in the wellbore using a downhole pump so as to avoid hydrocarbon flow at the surface (Whittle et al., 2003). The advantages of WFT are that, in most cases, the pressure test can be performed in a matter of minutes (WFT tools are highly interactive tools); representative reservoir fluid samples can be recovered; there is no surface production. The major limitation of WFT is generally agreed to be the scale of measurement, both in terms of producing pay and radius of investigation. In many cases predicting the future performance of the well is limited by the upscaling process that needs to be applied and the uncertainty degree dramatically increases in the presence of rock heterogeneity (Beretta et al., 2006).

\subsection{Production and Recovery}

Over the past decades, several interventions have been evaluated and/or experienced to reduce the oil industry's environmental impact on water and air quality. In the following an overview of adopted solutions for environmental issues concerning oil industry sector is provided.

\subsection{Water Quality}

From the late $90 \mathrm{sec}$ attention has been put on produced water disposal, particularly critical in off-shore conditions. It was primarily the Norwegian oil and gas industry that introduced the Environmental Impact Factor (EIF). This led to a better insight of the environmental impact of the individual toxic constituents, mainly aliphatic hydrocarbons, heavy aromatic compound (PAHs), Aromatics (BTEX) and Alkylated phenols (Grini et al., 2002; Knudsen et al., 2003).

Discharge option in offshore conditions requires appropriate technology adoption, such as the Performance Enhancing Coalescence one (PECT-F), for removing dispersed hydrocarbons (Grini et al., 2002). Nowadays, the most common approach for water disposal is represented by underground injection: it offers the benefits of conjugating the disposal issues with pressure support or EOR applications. The adoption of Downhole Oil/Water Separation (DOWS) also allows a 
reduction of water brought to surface and a minimization of groundwater contamination risks from tubing and casing (Godec and Johnson, 2005). In the United States more than $90 \%$ of the water produced from on-shore conventional wells is injected (Neff and Hagemann, 2007). In thermal EOR operations the produced water can be reused for steam generation, thus reducing the large volumes of water required in the process, after being treated to remove dissolved solids and organics (Neff and Hagemann, 2007).

Prevention philosophy is the other approach widely adopted to mitigate environmental problems related to water production: A great number of innovative techniques are devoted to water production minimization both during primary and assisted production. In conventional water flooding, the adoption of polymer flooding technique affects the mobility of the aqueous phase in order to increase the sweep efficiency and, thus, maximizing oil production and minimizing the water one (Silva et al., 2007).

One emerging application of nanotechnology is represented by the development of new types of "smart fluids" for water shut-off and improved/enhanced oil recovery. Compared with traditional approaches, the ultra-small size and very high surface area/volume ratios of nano-polymers allow higher operation efficiency with less involved active principle quantity and consequently more favorable economic conditions and minimization of environmental impact (Cocuzza et al., 2012).

\subsection{Air Quality}

Many companies develop air quality monitoring protocols for gaseous emissions management and air quality monitoring inside and around industrial operative sites, these protocols are also in compliance with local legislative authorities' requirements. As an example, in 2010 eni e and p developed the Air Quality Monitoring Standard, which was successfully implemented in Tunisia (Monfredini et al., 2012).

To reduce the emissions due to associated gas disposal, many company policies (Dyal et al., 1995; Ashiedu and Olarewaju-Alo, 1998) eliminate routine gas flaring operations. Moreover, emissions from wellcasing vent are collected and processed in order to separate fluids from the waste-gas stream. Noncondensable gas is then incinerated to reduce hydrocarbon and sulfur emissions into the atmosphere (Peavy and Braun, 1991).

Emissions reduction from combustion processes due to, for example, steam and power generation is dealt with by means of different strategies, such as: technology efficiency enhancement (i.e., pump and compressor efficiency) and process optimization, including waste heat recovery and application of energy conservation techniques. Other technologies are aimed at improving combustion performance, for example, dry low NOx combustion technology, selective catalyst reduction technology as well as water and steam injection, all aimed at reducing NOx emissions. In addition, emissioncontrol valves continue to be a leading processing equipment expenditure (Rana, 2010).

Inspired by the success of zeolites, which are materials capable of separating small gases such as oxygen and nitrogen, a new generation of large scale, lightweight and sturdy nanomembranes is being developed and deployed. Nanoporous and nanoparticular materials are also very promising to manage the environmental, health and safety risks deriving from the presence of $\mathrm{CO}_{2}$ and $\mathrm{H} 2 \mathrm{~S}$ in hydrocarbon mixtures (Cocuzza et al., 2012).

An alternative to overcome the $\mathrm{CO}_{2}$ emission problem is the carbon dioxide capture and sequestration in underground storages, or its use as a flooding agent for EOR processes as discussed below.

\subsection{Carbon Capture and Storage}

It is the general consensus that the emission of Carbon Dioxide $\left(\mathrm{CO}_{2}\right)$ into the atmosphere has been progressively increased due to industrial activities. Excessive emission of $\mathrm{CO}_{2}$ is considered as one of main causes of the greenhouse effect and of the resulting negative changes in climate (Saptharishi and Makwana, 2011). For years governments as well as the scientific community have shown a growing interest in the possibility of reducing the concentration of $\mathrm{CO}_{2}$ into the atmosphere. One of the most discussed options has been the Carbon dioxide Capture and Storage (CCS). Currently, the Global CCS Institute identifies 73 industrial-scale CCS projects around the world (GCCSI, 2012).

$\mathrm{CCS}$ process consists in the separation of $\mathrm{CO}_{2}$ from industrial and energy-related sources, its transport to a natural storage location and its long-term isolation from the atmosphere. The capture step involves separating $\mathrm{CO}_{2}$ from other gaseous products. The $\mathrm{CO}_{2}$ capture process is likely to be applied in large point sources: fossil fuel power plants, fuel processing plants and other industrial plants, particularly for those that manufacture iron, steel, cement and bulk chemicals. When captured $\mathrm{CO}_{2}$ has to be properly injected into a geological formation able to safely contain the gas and to prevent 
leakage in significant quantities. Depleted oil and gas reservoirs, deep saline formations and unminable coal beds represent the favorite candidates for safe geological storage of $\mathrm{CO}_{2}$. Furthermore, the combination of $\mathrm{CO}_{2}$ storage with Enhanced Oil Recovery or Enhanced Coal Bed Methane recovery can, not only reduce greenhouse emissions, but also, award economic benefits due to additional revenues from the oil or gas recovery.

The main industry with the technology and the scientific knowledge necessary to develop $\mathrm{CO}_{2}$ storage projects in deep, onshore or offshore geological formations is the oil industry. Over the last few years, oil and natural gas companies have been actively carrying out innovative research and promoting new technology initiatives to answer the technical and policy issues regarding CCS.

Despite the attractive environmental benefits related to carbon storage, its application is often hampered by economic and logistic reasons, such as cost-effectiveness of transport particularly for long distances between the production site and the storage one. The industry is already subjected to strict national and international regulations to ensure health and safety and environmental protection and international standards for CCS are being developed by the International Organization for Standardization (ISO). With appropriate site selection based on subsurface information, a monitoring program, a regulatory system and the appropriate use of remediation methods to stop or control eventual $\mathrm{CO}_{2}$ release, the local health, safety and environment risks of geological storage would be comparable to the ones of current activities such as natural gas storage, EOR and deep underground disposal of acid gas (IPCC, 2005).

\section{CONCLUSION}

Due to more restrictive environmental regulations, a stronger social environmental concern and a general need to reduce industry footprint, the oil industry has placed great emphasis on the sustainable development of its operations in all the life phases of a hydrocarbon reservoir: From appraisal to field development, from production and recovery to reservoir decommissioning.

In fact, many companies apply proper waste plan for gas emission management and produced water disposal, during the appraisal phase as well as the production operations. The $\mathrm{CO}_{2}$ storage as byproduct of enhanced oil recovery strategy is an example. Prevention philosophy is another approach widely adopted to mitigate environmental problems: for example, in the appraisal phase the use of unconventional techniques guarantees significant gas emission reduction. Moreover, water production minimization can be strongly enhanced thanks to polymer adoption in conventional water flooding.

The oil industry is facing important technical challenges which make it move towards more efficient, less expensive and environmentally friendly solutions. Growing expectation is placed in new emerging technologies, such as nanotechnology, which has already offered some breakthroughs in innovative and environmentally friendly technologies in many other industrial fields.

However, besides the environmental benefit, costeffectiveness, legal requirements and anticipated future technological developments are determining factors in the decision to implement a green project.

\section{REFERENCES}

Adesina, F., A. Anthony, A. Gbadegesin and O. Eseoghene, 2012. Environmental impact evaluation of a safe drilling mud. Proceedings of the SPE Middle East Health, Safety, Security Environment Conference Exhibition, Apr. 2-4, Abu Dhabi, UAE. DOI: 10.2118/152865-MS

Amin, R.A.M., D.K. Clapper, J.E. Norfleet, M.J. Otto and T. Xiang et al., 2010. Joint development of an environmentally acceptable ester-based drilling fluid. Proceedings of the Trinidad and Tobago Energy Resources Conference, Jun. 27-30, Port of Spain, Trinidad. DOI: 10.2118/132693-MS

Ashiedu, R.I. and B.O Olarewaju-Alo, 1998. Utilisation of "Waste" gas and water streams: An example of environmental impact relduction effort during field development planning in the niger delta. Proceedings of the SPE International Conference on Health, Safety and Environment in Oil and Gas Exploration and Production, Jun. 7-10, IEEE Xplore Press, Caracas, Venezuela. DOI: 10.2118/46568-MS

Beretta, E., A. Tiani, G.L. Presti and F. Verga, 2006. Injection tests as a reliable alternative to conventional well testing: A Real Field Experience. Proceedings of the SPE Europec/EAGE Annual Conference and Exhibition, Jun. 12-15, SPE 100283, Vienna, Austria. DOI: 10.2118/100283-MS

Beretta, E., A. Tiani, G.L. Presti and F. Verga, 2007. Value of injection testing as an alternative to conventional well testing: Field experience in a sour-oil reservoir. SPE Reservoir Evaluat. Eng., 10: 112-121. DOI: 10.2118/100283-PA 
Cancelliere, M. and F. Verga, 2012. Simulation of unconventional well tests with the finite volume method. Petroleum Sci., 9: 317-329. DOI: 10.1007/s12182-001-0215-6

Cocuzza, M., C. Pirri, V. Rocca and F. Verga, 2012. Current and Future nanotech applications in the oil industry. Am. J. Applied Sci., 9: 784-793. DOI: 10.3844/ajassp.2012.784.793

Coelho, A.C.D., C.D. Carmargo, E.T. Kato and V.M.Q.F. Legrand, 2005. Utilizing mini-dst for formation evaluation. Proceedings of the SPE Latin American and Caribbean Petroleum Engineering Conference, Jun. 20-23, Rio de Janeiro, Brazil, pp: 13-13. DOI: 10.2118/94963-MS

Dyal, S., A. Nijhawan and K. Ramnath, 1995. Environmental management strategies for an enhanced oil recovery project, Trinidad. Proceedings of the SPE Annual Technical Conference and Exhibition, Oct. 22-25, Dallas, Texas,USA. DOI: 10.2118/30689-MS

GCCSI, 2012. Global status of large-scale integrated projects. Global CCS Institute.

Godec, M.L. and N. Johnson, 2005. Quantifying environmental benefits of improved oil and gas exploration and production technology. Proceedings of the SPE/EPA/DOE Exploration and Production Environmental Conference, Mar. 7-9, Galveston, Texas. DOI: 10.2118/94388-MS

Gogan, R., V. Mattia, M. Oates, S. Gumarov and T. Shokanov et al., 2010. Cuttings re-injection as an environmentally safe and economically efficient drilling waste management option for karachaganak field. Proceedings of the Caspian Carbonates Technology Conference, Nov. 8-10, Atyrau, Kazakhstan.

Grini, P.G., M. Hjelsvold and S. Johnsen, 2002. Choosing produced water treatment technologies based on environmental impact reduction. Proceedings of the SPE International Conference on Health, Safety and Environment in Oil and Gas Exploration and Production, Mar. 20-22, Kuala Lumpur, Malaysia. DOI: 10.2118/74002-MS

Hollaender, F., J.G. Filas, C.O. Bennett and A.C. Gringarten, 2002. Use of downhole production/reinjection for zero-emission well testing: Challenges and rewards. Proceedings of the SPE Annual Technical Conference and Exhibition, Sept. 29-Oct. 2, San Antonio, Texas, pp: 10-10. DOI: $10.2118 / 77620-\mathrm{MS}$
IPCC, 2005. IPCC Special Report on Carbon Dioxide Capture and Storage. In: Prepared by Working Group III of the Intergovernmental Panel on Climate Change, Metz, B., O. Davidson, H.C.D. Coninck, M. Loos and L.A. Meyer (Eds.), Cambridge University Press, Cambridge, United Kingdom and New York, USA.

Khan, F., B. Sinanan, R. Jokhoo, F Innis and V. Ramlogan, 2005. Health, safety and environmental risk mitigation for a thermal oil recovery pilot facility in trinidad. Proceedings of the SPE International Improved Oil Recovery Conference in Asia Pacific, Dec. 5-6, Kuala Lumpur, Malaysia. DOI: 10.2118/97655-MS

Knudsen, B.L., M. Hjelsvold, T.K. Frost, M.B. Eiken and P.G. Grini et al., 2003. Toward zero environmental impact of the produced water. Proceedings of the Offshore Europe, Sept. 2-5, Society of Petroleum Engineers, Aberdeen, United Kingdom. DOI: 10.2118/83994-MS

Levitan, M.M., 2002. Application of water injection/falloff tests for reservoir appraisal: New analytical solution method for two-phase variable rate problems. Proceedings of the SPE Annual Technical Conference and Exhibition, Sept. 29- Oct. 2, San Antonio, Texas, pp: 11-11. DOI: 10.2118/77532MS

Monfredini, C., G. Aiello, A. Tegami, M. Morichini and A. Stillavato et al., 2012. Upstream air quality monitoring and emissions. Proceedings of the International Conference on Health, Safety and Environment in Oil and Gas Exploration and Production, Sept. 11-13, Perth, Australia. DOI: 10.2118/156645-MS

Neff, J.M. and R. Hagemann, 2007. Environmental challenges of heavy crude oils: Management of liquid wastes. Proceedings of the E andP Environmental and Safety Conference, Mar. 5-7, Galveston, Texas, USA. DOI: $10.2118 / 101973-M S$

Novelli, L., M. Sella, D. Giacca, R. Mazzei and M. Croce et al., 2005. Hydrocarbons: origin, exploration and production. Eni Corporate University.

Peavy, M.A. and J.E. Braun, 1991. Control of waste gas from a thermal eor operation. J. Petroleum Technol., 43: 656-661. DOI: 10.2118/21766-PA

Rana, S., 2010. Environmental regulations, technology and cost of compliance for oil and gas operations. Proceedings of the Trinidad and Tobago Energy Resources Conference, Jun. 27-30, Port of Spain, Trinidad. DOI: 10.2118/134256-MS 
Saptharishi, P. and M. Makwana, 2011. Technical and Geological review of carbon dioxide geo sequestration along with analysis and study of various monitoring techniques. Proceedigns of the International Petroleum Technology Conference, Feb.7-9, Bangkok, Thailand. DOI: 10.2523/15402MS

Shaaban, S.I., 2000. Environmental control. Proceedings of the SPE International Conference on Health, Safety and the Environment in Oil and Gas Exploration and Production held in Stavanger, Jun. 26-28, Norway.

Silva, I.P.G.D., M.A. Melo, J.M. Luvizotto and E.F. Lucas, 2007. Polymer Flooding: A sustainable enhanced oil recovery in the current scenario. Proceedings of the Latin American and Caribbean Petroleum Engineering Conference, Apr. 15-18. Buenos Aires, Argentina. DOI: 10.2118/107727-MS

Soliman, M.Y., M. Azari, J. Ansah and C.S. Kabir, 2005. Review and application of short-term pressure transient testing of wells. Proceedings of the 14th SPE Middle East Oil and Gas Show and Conference, Mar. 4-5, Bahrain, pp: 14-14. DOI: 10.2118/93560MS

Swanston, H.W. and H.R. Heffler, 1977. Environmental considerations in waste disposal from drilling in the shallow beaufort sea. The J. Canadian Petroleum, 10: 116-122. DOI: 10.2118/77-03-11

Verga, F. and V. Rocca, 2010. Green methodologies to test hydrocarbon reservoirs. Am. J. Environ. Sci., 6: 1-10. DOI:10.3844/ajessp.2010.1.10

Verga, F., D. Viberti and E. Salina Borello, 2008. A new 3-d numerical model to effectively simulate injection tests. Proceedings of the SPE Europec/EAGE Annual Conference and Exhibition, June, 9-12, Rome, Italy, pp: 9-12. DOI: 10.2118/113832-MS
Verga, F., D. Viberti and E. Salina Borello, 2011. A new insight for reliable interpretation and design of injection tests. J. Petroleum Sci. Eng., 78: 166-177. DOI: $10.1016 /$ j.petrol.2011.05.002

Verga, F., D., Viberti and C. Serazio, 2012. Estimation of skin components for a partially completed damaged well from injection tests. J. Petroleum Sci. Eng., 90-91: 165-174. DOI: 10.1016/j.petrol.2012.04.024

Viberti, D and F. Verga, 2012. An approach for the reliable evaluation of the uncertainties associated to petrophysical properties. Math. Geosci., 44: 327341. DOI: $10.1007 / \mathrm{s} 11004-011-9358-1$

Whittle, T.M., J. Lee and A.C. Gringarten, 2003. Will wireline formation tests replace well tests? Proceedings of the SPE Annual Technical Conference and Exhibition, Oct. 5-8, Denver, Colorado, pp: 12-12. DOI: 10.2118/84086-MS

Woie, R., T.M. Hegre, T. Gravema and P.E. Berger, 2000. Downhole production testing, a cost effective, safe and environmentally friendly well test method. Proceedings of the SPE International Conference on Health, Safety and Environment in Oil and Gas Exploration and Production, Jun. 26-28, Stavanger, Norway, pp: 11-11. DOI: 10.2118/61183-MS

Xiaoqing, H. and Z. Lihui, 2009. Research on the application of environment acceptable modified natural macromolecule based drilling fluid. Proceedings of the Asia Pacific Health, Safety, Security and Environment Conference, Aug. 4-6, Jakarta, Indonesia. DOI: 10.2118/123232-MS 